\title{
A Different Perspective for Coaching and Training Education According to Score Changes During Rhythmic Gymnastics European Championships
}

\author{
Berfin Serdil ÖRS ${ }^{1}$ \\ ${ }^{1}$ Department of Coaching Education, Faculty of Sport Sciences, Aydin Adnan Menderes University, Aydin, \\ Turkey \\ Correspondence: Berfin Serdil ÖRS, Department of Coaching Education, Faculty of Sport Sciences, Aydin Adnan \\ Menderes University, 09100, Aydin, Turkey. E-mail: bsutcu@adu.edu.tr
}

Received: December 30, 2020

Accepted: February 26, 2021

Online Published: April 25, 2021

doi:10.5539/ies.v14n5p63

URL: https://doi.org/10.5539/ies.v14n5p63

\begin{abstract}
Rhythmic gymnasts repeat elements thousands of times which may put a risk on gymnasts' health. It is necessary to protect the current and future health conditions of young gymnasts, especially in the growth process. There is a lack of knowledge about training education on rhythmic gymnastics. To suggest innovative changes, the current study aimed to analyze the scores (D, E, and total scores) of the first 24 gymnasts competing in 34th and 36th Rhythmic Gymnastics European Championships (ECh). Research data were collected from 24 rhythmic gymnasts' scores, from the $34^{\text {th }} \mathrm{ECh}$ and $36^{\text {th }} \mathrm{ECh}$. Difficulty (D), Execution (E), and total scores for hoop, ball, clubs, ribbon were analyzed. Conformity of data to normal distribution was assessed with the Kolmogorov-Smirnov test. Variables with normal distribution were compared by one-way analysis of variance (ANOVA)/independent samples t-test and for variables not fitting normal distribution, Mann Whitney U/Kruskal Wallis H test was used. The main findings of the current study were that D scores between 2018 and 2020 increased approximately 4.18 points $(p<0.001)$ while $E$ scores showed no significant changes $(p>0.05)$. In all apparatus total scores increased $+15.39(p<0.001)$. As these increases seem to be in the faith of gymnasts to get higher results, it is obvious that gymnasts are forced to have a higher number of elements in their routines. Coaches should be informed about new training models and coaching education systems. In this way, they will be able to support their gymnasts in all ways (not only with performance development but also with recent updates on training educations).
\end{abstract}

Keywords: coaching education, difficulty score, rhythmic gymnastics, training education

\section{Introduction}

Rhythmic gymnastics is an Olympic sport event and in this sport, gymnasts perform their routines by coordinating body elements with the handling of an apparatus (rope, hoop, ball, clubs, ribbon) in a choreographic composition accompanied by music (Sierra-Palmeiro, Bobo-Arce, Pérez-Ferreirós, \& Fernández-Villarino, 2019). Competitions in rhythmic gymnastics consist of two programs: (1) individual and (2) group. Senior individual gymnasts usually compete with four apparatus and the duration of a routine ranges from 1'15" to 1'30" (FIG, 2017).

In sports with high artistic aspects, judges rank the performance by evaluating pre-established parameters. The scores assigned to a routine are determined depending on relative comparisons to a set of movements considered to be excellent with concerning to form and execution. During a competition, judges are obliged to analyze each movement in detail and give the appropriate score to the whole choreography following pre-established standards (Díaz-Pereira, Gómez-Conde, Escalona, \& Olivieri, 2014). In rhythmic gymnastics with high artistic and aesthetic aspects, the performance is evaluated by both quantitative and qualitative criteria specified in the Code of Points (CoP). The CoP is set by the International Gymnastics Federation (FIG) and is updated after every Olympic Games (Sierra-Palmeiro et al., 2019). For the past 20 years, FIG has made numerous changes to the rules to increase the objectivity of judging and scores, and to stimulate the development of rhythmic gymnastics (Sierra-Palmeiro et al., 2019). Looking at the current rules determined by FIG, it is seen that each jury consists of two groups of judges: (1) Difficulty (D) and (2) Execution (E). Besides, each D and E panel have their subgroups. While D score is determined by the sum of two partial $\left(\mathrm{D}_{1}-\mathrm{D}_{2}\right.$ and $\left.\mathrm{D}_{3}-\mathrm{D}_{4}\right) \mathrm{D}$ scores, execution score is the sum of the artistic $\left(\mathrm{E}_{1}-\mathrm{E}_{2}\right)$ 
and technical $\left(\mathrm{E}_{3}-\mathrm{E}_{4}-\mathrm{E}_{5}-\mathrm{E}_{6}\right)$ deductions subtracted from 10.00 points. D panel for the individual program is composed of four parts: (1) Body Difficulties (BD), (2) Dance Steps Combinations (S), (3) Dynamic Elements with Rotation (DER), and (4) Apparatus Difficulty (AD) (FIG, 2017). Since 2013 body difficulties consist of jumps/leaps, balances, and rotations (Agopyan \& Örs, 2019). Gymnasts may increase their D scores not only with body difficulties but also by performing apparatus difficulties. Recent rules allow gymnasts to perform an unlimited number of $\mathrm{ADs}$ and the base value for an $\mathrm{AD}$ is 0.20 points. This score may be increased by changing the base of $\mathrm{AD}$ (catch or rebound from the floor or a part of the body from a large throw, etc.) (FIG, 2017). At the end of 2017, FIG rhythmic gymnastics technical committee decided to remove the maximum limit for D score. This change led to substantial modifications in the related scores $\left(D_{1}-D_{2}\right.$ and $\left.D_{3}-D_{4}\right)$ and therefore in the final score (Chiriac, Teodorescu \& Bota, 2020). On the other hand, for the execution component, judges evaluate the performance quality during the routines and also deduct technical and artistic faults (Batista, Gomes, Garnagta, \& Ávila-Carvalho, 2018).

Rhythmic gymnastics has a complex structure and because of this nature requires a specific training process because it is an early specialization sport (Balyi, Way \& Higgs, 2013) and this earlier specialization starts before bone maturation. Rhythmic gymnastics training requires many hours of intensive training, a large volume of training, and a high number of element repetitions to perform a high level of technical elements. It is thought that intensive training programs during growth and developmental period may affect the gymnasts' health. In addition to these intensive training programs, gymnasts should also pay attention to their nutrition to maintain their body weight and keep their performance at a high level (Bulca \& Ersöz, 2004). In the literature, significant problems with eating disorders were identified in female athletes (Di Cagno et al., 2018). For these reasons, it is thought that the growth and development processes of rhythmic gymnasts are suppressed compared to girls of the same age who do not engage in this sport (Bulca \& Ersöz, 2004). Considering that rhythmic gymnasts are still in the development stage when they start to compete at the World Championships (especially juniors); it is necessary to protect the current and future health conditions of young gymnasts, especially in the growth process (Agopyan, 2020). However, gymnasts can participate in a high-level international competition from the age of 13 and one of these competitions is the continental championships such as European Championships (ECh).

Continental championships have the feature of Olympic quota and the European continent is contained within European Gymnastics. Even though ECh in rhythmic gymnastics takes place every year, participation criteria and rules differ for odd and even years (European Gymnastics, Technical Regulations 2020). Even though a total of four ECh were held between 2017-2020, the content of the competitions changed for each year. In 2017 and 2019 senior individual qualification and junior group competitions were held. On the other hand, junior individuals, senior individual all-around finals, and senior groups competitions took place for 2018 and 2020. ECh is important to take an Olympic quota therefore it is crucial to have a score analysis of these competitions to help the improvement of rhythmic gymnastics. However, to the best of our knowledge, this situation has not been revealed in the literature. It is seen that some studies analyzed individual and group routines to understand the performance and to specify the determinants of performance in rhythmic gymnastics (Agopyan, 2014; Agopyan \& Örs, 2019; Ávila-Carvalho, Klentrou \& Lebre, 2012; Chiriac, Teodorescu \& Bota, 2019; Trifunov \& Dobrijević, 2013). Studies highlight that gymnasts tend to choose the same body difficulty elements which led to the lack of variation in body difficulties (Agopyan, 2014; Agopyan \& Örs, 2019). Moreover, Örs (2020) analyzed the effect of difficulty and execution scores on total ranking during the 2019 Rhythmic Gymnastics World Championships (individual all-around finals). The author stated that the technical ability of gymnasts influences qualification score and ball D score was found to be one the most effective score on ranking (Örs, 2020). Finally, Agopyan (2020) analyzed the movements with or without the backbend of the trunk or large hip extension in $1^{\text {st }}$ Juniors' Rhythmic Gymnastics World Championship-2019 and reported that gymnasts tend to choose hyperextension movements which may pose a risk of injury in columna vertebralis and hip region of the rhythmic gymnasts. Even that, there are studies to understand the structure of the routines and to determine the most preferred element for the most effective score on ranking on the contrary looking at the training requirements in rhythmic gymnastics, coaches, judges, gymnasts and all other people involved in rhythmic gymnastics do not want to explain their training programs because they compete with each other. This is one of the reasons why there is a lack of references about this topic (Bobo-Arce \& Méndez-Rial, 2013). On the other hand, one of the coaches' goals in the sport is to achieve the best results in a competition by protecting the health of the athletes (Di Cagno et al., 2018). To the best of our knowledge, there are no studies conducted in the literature to determine the score changes in the senior individual gymnasts competing in European Championships all-around finals with new changes in the rules (2018 and 2020). For this reason, the current study aimed to analyze the scores (D, E, and total scores) of the first 24 gymnasts who competed in the $34^{\text {th }}$ Rhythmic Gymnastics European Championships (Guadalajara, 2018) and the $36^{\text {th }}$ Rhythmic Gymnastics European Championship (Kyiv, 2020), which are considered as senior individual all-around finals. It 
was aimed to determine the increases and decreases in the D, E and as well as total scores in an Olympic cycle. Besides, gymnasts may be under pressure because of long training hours and intensive training programs. By analyzing D, E, and total score changes in two different European Championships, it is aimed to suggest innovative changes that can be made in the rules depending on the performance to protect both the beauty of the sport and the gymnasts' health. Moreover, it was also aimed to draw attention to the issues of coaching educations regarding the training programs and training requirements in rhythmic gymnastics and gymnasts' health.

\section{Method}

\subsection{Data Collection}

The research data were collected from 24 individual senior rhythmic gymnasts' scores (from senior individual all-around finals) of the $34^{\text {th }}$ European Rhythmic Gymnastics Championships (Guadalajara, 2018) and $36^{\text {th }}$ European Rhythmic Gymnastics Championships (Kyiv, 2020). The female gymnasts were from 26 different Europe countries.

\subsection{Ethics}

This study was conducted as an observational study with publicly available data. Competition data were obtained from the results books of the $34^{\text {th }}$ ECh (https://www.europeangymnastics.com/event/2018-european-championships-rhythmic-gymnastics/results) and $36^{\text {th }} \quad$ ECh $\quad$ (https://www.europeangymnastics.com/event/2020-european-championships-rhythmic gymnastics/results) published at the European Gymnastics' official website. As the results were available online in an unprocessed format and were not collected through experimentation there are no ethical concerns (Morley \& Thomas, 2005).

\subsection{Procedures}

The analysis was carried out on hoop D-E, ball D-E, clubs D-E, ribbon D-E, and total scores. A total of 624 scores were analyzed during the current study. The analyzed scores were determined as follows:

- 48 hoop D scores (24 scores from $34^{\text {th }} \mathrm{ECh}+24$ scores from $\left.36^{\text {th }} \mathrm{ECh}\right)$

- 48 hoop E scores (24 scores from $34^{\text {th }} \mathrm{ECh}+24$ scores from $\left.36^{\text {th }} \mathrm{ECh}\right)$

- 48 hoop total scores (24 scores from $34^{\text {th }} \mathrm{ECh}+24$ scores from $\left.36^{\text {th }} \mathrm{ECh}\right)$

- 48 ball D scores (24 scores from $34^{\text {th }} \mathrm{ECh}+24$ scores from $36^{\text {th }} \mathrm{ECh}$ )

- 48 ball E scores (24 scores from $34^{\text {th }} \mathrm{ECh}+24$ scores from $\left.36^{\text {th }} \mathrm{ECh}\right)$

- 48 ball total scores (24 scores from $34^{\text {th }} \mathrm{ECh}+24$ scores from $\left.36^{\text {th }} \mathrm{ECh}\right)$

- 48 clubs D scores (24 scores from $34^{\text {th }} \mathrm{ECh}+24$ scores from $36^{\text {th }} \mathrm{ECh}$ )

- 48 clubs E scores (24 scores from $34^{\text {th }} \mathrm{ECh}+24$ scores from $\left.36^{\text {th }} \mathrm{ECh}\right)$

- 48 clubs total scores (24 scores from $34^{\text {th }} \mathrm{ECh}+24$ scores from $36^{\text {th }} \mathrm{ECh}$ )

- 48 ribbon D scores (24 scores from $34^{\text {th }} \mathrm{ECh}+24$ scores from $36^{\text {th }} \mathrm{ECh}$ )

- 48 ribbon E scores (24 scores from $34^{\text {th }} \mathrm{ECh}+24$ scores from $36^{\text {th }} \mathrm{ECh}$ )

- 48 ribbon total scores (24 scores from $34^{\text {th }} \mathrm{ECh}+24$ scores from $36^{\text {th }} \mathrm{ECh}$ )

- 48 total scores [sum of the total hoop, ball, clubs, and ribbon scores from $34^{\text {th }} \mathrm{ECh}(24$ total scores $)+36^{\text {th }} \mathrm{ECh}$ (24 total scores)].

\subsection{Statistical Analysis}

The statistical analysis of the study data was made using SPSS 22.0 software (SPSS Inc., Chicago, IL). Conformity of the data to normal distribution was assessed with the Kolmogorov-Smirnov test. Variables with normal distribution were compared by one-way analysis of variance (ANOVA) or independent samples t-test and for variables not fitting normal distribution, the Mann Whitney $\mathrm{U}$ or Kruskal Wallis $\mathrm{H}$ test was used. Mean \pm standard deviation and median $\left(25^{\text {th }}-75^{\text {th }}\right.$ percentiles) were used for data normally distributed, not distributed; respectively. A value of $\mathrm{p}<0.05$ was accepted as statistically significant.

\section{Results}

Descriptive statistics and comparisons of scores according to year and apparatus are given in Table 1-3. 
Table 1. Descriptive statistics and comparison of scores according to years (D, E, and total scores are the sum of hoop, ball, clubs and ribbon)

\begin{tabular}{|c|c|c|c|c|}
\hline \multirow{2}{*}{$\begin{array}{c}\text { Scores } \\
\text { (points) }\end{array}$} & \multicolumn{2}{|c|}{$\begin{array}{c}\text { YEARS } \\
\text { Mean } \pm \text { SD } \\
\text { Median }\left(25^{\text {th }}-75^{\text {th }} \text { Percentiles }\right)\end{array}$} & \multirow[b]{2}{*}{ Differences } & \multirow[t]{2}{*}{$\mathrm{p}$} \\
\hline & $\begin{array}{c}2018 \\
(\mathrm{n}=96)\end{array}$ & $\begin{array}{c}2020 \\
(\mathrm{n}=96)\end{array}$ & & \\
\hline D score & $\begin{array}{c}9.12 \pm 1.22 \\
9.00(8.20-9.98) \\
\end{array}$ & $\begin{array}{c}13.30 \pm 2.38 \\
13.50(11.28-15.00)\end{array}$ & +4.18 & $<0.001^{\mathrm{a}^{*}}$ \\
\hline E score & $\begin{array}{c}7.75 \pm 0.79 \\
7.750(7.30-8.30)\end{array}$ & $\begin{array}{c}7.44 \pm 1.28 \\
7.50(6.65-8.44)\end{array}$ & -0.31 & $0.237^{\mathrm{a}}$ \\
\hline Total score & $\begin{array}{c}67.43 \pm 6.53 \\
68.31(63.13-70.33)\end{array}$ & $\begin{array}{c}82.82 \pm 13.45 \\
87.15(74.63-92.80)\end{array}$ & +15.39 & $<0.001^{\mathrm{b}^{*}}$ \\
\hline
\end{tabular}

Note. ${ }^{*} \mathrm{p}<0.001$; a: Mann-Whitney U test; b: Independent samples t-test.

Minimum and maximum D scores were 5.80 and 12.10 respectively in 2018. However, in 2020, both minimum and maximum scores were higher (5.60 and 17.40; respectively). The D scores and total scores were statistically different between years. The mean D scores for all four apparatus in 2020 were 4.18 points higher than in 2018 $(\mathrm{p}<0.001)$. Total scores (sum of four apparatus) were also found to be statistically different between the years and the total score in 2020 was 15.39 points higher than in 2018. There were no significant differences between 2018 and 2020 EChs for E scores ( $>0.05$ ) (Table 1). While minimum and maximum E scores in 2018 were 4.95 and 9.10 ; in 2020 they were 3.30 and 9.30 respectively.

Table 2. Descriptive statistics and comparison of D, E, and total scores (sum of 2018 and 2020) of each apparatus according to apparatus

\begin{tabular}{|c|c|c|c|c|c|}
\hline \multirow{2}{*}{$\begin{array}{l}\text { Apparatus scores } \\
\text { (points) }\end{array}$} & \multicolumn{4}{|c|}{$\begin{array}{c}\text { APPARATUS } \\
\text { Mean } \pm \text { SD } \\
\text { Median }\left(25^{\text {th }}-75^{\text {th }} \text { Percentiles }\right)\end{array}$} & \multirow[t]{2}{*}{$\mathrm{p}$} \\
\hline & $\begin{array}{c}\text { Hoop } \\
(\mathrm{n}=48)\end{array}$ & $\begin{array}{c}\text { Ball } \\
(\mathrm{n}=48)\end{array}$ & $\begin{array}{c}\text { Clubs } \\
(\mathrm{n}=48)\end{array}$ & $\begin{array}{l}\text { Ribbon } \\
(\mathrm{n}=48)\end{array}$ & \\
\hline \multirow{2}{*}{ D score } & $11.58 \pm 2.84$ & $11.70 \pm 2.74$ & $11.45 \pm 3.00$ & $10.12 \pm 2.46$ & \multirow{2}{*}{$0.010^{\mathrm{a}}$} \\
\hline & $10.90(9.15-14.18)$ & $10.70(9.63-14.58)$ & $10.70(8.83-14.40)$ & $9.60(7.80-12.58)^{*}$ & \\
\hline \multirow{2}{*}{ E score } & $7.72 \pm 1.06$ & $7.70 \pm 1.13$ & $7.49 \pm 1.10$ & $7.46 \pm 0.99$ & \multirow{2}{*}{$0.274^{\mathrm{a}}$} \\
\hline & $7.85(7.20-8.58)$ & $7.93(6.93-8.49)$ & $7.75(6.91-8.20)$ & $7.38(6.89-8.20)$ & \\
\hline \multirow{2}{*}{ Total scores of each apparatus } & $19.25 \pm 3.56$ & $19.37 \pm 3.33 * *$ & $18.92 \pm 3.59$ & $17.57 \pm 3.04$ & \multirow{2}{*}{$0.038^{\mathrm{b}}$} \\
\hline & $18.45(16.53-21.83)$ & $18.68(16.59-22.06)$ & $18.23(16.31-22.01)$ & $16.78(15.25-20.16)$ & \\
\hline
\end{tabular}

Note. *Ribbon $\mathrm{D}$ score is significantly different from hoop $(\mathrm{p}=0.034 ; \mathrm{p}<0.05)$ and ball $(\mathrm{p}=0.016 ; \mathrm{p}<0.05)$ score; **Total ball score is significantly different than total ribbon score $(\mathrm{p}=0.048 ; \mathrm{p}<0.05)$; $\mathrm{a}$ : Kruskal Wallis $\mathrm{H}$ test; $\mathrm{b}$ : One-way ANOVA.

The sum of scores for 2018 and 2020 was compared according to apparatus by one-way ANOVA test. The ANOVA analysis showed $\mathrm{D}(\mathrm{p}=0.010)$ and the total scores of each apparatus $(\mathrm{p}=0.038)$ showed statistically significant differences. Furthermore, scores for ribbon were found to be statistically different than hoop and ball. Ribbon D score was lower than hoop and ball D scores. Also, the total score for the ball was found to be statistically higher and different from the ribbon (Table 2). 
Table 3. Descriptive statistics and comparison of scores according to apparatus and years

\begin{tabular}{|c|c|c|c|c|}
\hline \multirow[t]{2}{*}{$\begin{array}{c}\text { APPARATUS SCORES } \\
\text { (Points) }\end{array}$} & \multicolumn{2}{|c|}{$\begin{array}{l}\text { YEARS } \\
\text { Mean } \pm \text { SD } \\
\left(25^{\text {th }}-75^{\text {th }} \text { Percentiles }\right)\end{array}$} & \multirow[b]{2}{*}{ Differences } & \multirow[t]{2}{*}{$\mathrm{p}$} \\
\hline & $2018(\mathrm{n}=24)$ & $2020(\mathrm{n}=24)$ & & \\
\hline Hoop D & $\begin{array}{c}9.52 \pm 1.35 \\
9.55(8.70-10.15) \\
\end{array}$ & $\begin{array}{c}13.64 \pm 2.41 \\
14.15(11.93-15.63) \\
\end{array}$ & +4.12 & $<0.001^{\mathrm{a}^{*}}$ \\
\hline Ball D & $\begin{array}{c}9.60 \pm 0.99 \\
9.75(8.73-10.30)\end{array}$ & $\begin{array}{c}13.79 \pm 2.27 \\
14.45(11.65-15.50) \\
\end{array}$ & +4.19 & $<0.001^{\mathrm{a}^{*}}$ \\
\hline Clubs D & $\begin{array}{c}9.06 \pm 1.18 \\
8.90(8.28-9.98) \\
\end{array}$ & $\begin{array}{c}13.85 \pm 2.24 \\
14.40(12.25-15.38) \\
\end{array}$ & +4.79 & $<0.001^{\mathrm{a}^{*}}$ \\
\hline Ribbon D & $\begin{array}{c}8.31 \pm 0.90 \\
8.20(7.63-8.90)\end{array}$ & $\begin{array}{c}11.93 \pm 2.18 \\
12.55(10.63-13.40) \\
\end{array}$ & +3.62 & $<0.001^{\mathrm{a}^{*}}$ \\
\hline Hoop E & $\begin{array}{c}7.78 \pm 0.88 \\
7.85(7.43-8.31) \\
\end{array}$ & $\begin{array}{c}7.67 \pm 1.22 \\
7.78(7.00-8.70) \\
\end{array}$ & -0.11 & $0.732^{\mathrm{a}}$ \\
\hline Ball E & $\begin{array}{c}7.97 \pm 0.71 \\
7.93(7.63-8.48) \\
\end{array}$ & $\begin{array}{c}7.42 \pm 1.40 \\
7.78(6.68-8.53)\end{array}$ & -0.57 & $0.095^{\mathrm{a}}$ \\
\hline Clubs E & $\begin{array}{c}7.65 \pm 0.79 \\
7.80(7.19-8.00) \\
\end{array}$ & $\begin{array}{c}7.33 \pm 1.33 \\
7.48(6.71-8.29) \\
\end{array}$ & -0.32 & $0.386^{\mathrm{b}}$ \\
\hline Ribbon E & $\begin{array}{c}7.59 \pm 0.74 \\
7.38(7.05-8.20)\end{array}$ & $\begin{array}{c}7.33 \pm 1.19 \\
7.60(6.50-8.31)\end{array}$ & -0.26 & $0.642^{b}$ \\
\hline Total hoop & $\begin{array}{c}17.24 \pm 2.23 \\
17.16(16.41-18.48) \\
\end{array}$ & $\begin{array}{c}21.25 \pm 3.55 \\
21.55(18.23-24.45) \\
\end{array}$ & +4.01 & $<0.001^{\mathrm{a}^{*}}$ \\
\hline Total ball & $\begin{array}{c}17.57 \pm 1.66 \\
17.78(16.51-18.71) \\
\end{array}$ & $\begin{array}{c}21.17 \pm 3.62 \\
21.93(18.14-23.84) \\
\end{array}$ & +3.60 & $0.001^{\mathrm{b}^{*}}$ \\
\hline Total clubs & $\begin{array}{c}16.69 \pm 1.88 \\
16.65(15.78-17.99) \\
\end{array}$ & $\begin{array}{c}21.15 \pm 3.54 \\
21.93(19.03-23.69) \\
\end{array}$ & +4.46 & $0.001^{\mathrm{a}^{*}}$ \\
\hline Total ribbon & $\begin{array}{c}15.92 \pm 1.51 \\
15.53(14.88-16.60)\end{array}$ & $\begin{array}{c}19.22 \pm 3.31 \\
19.88(17.23-21.85)\end{array}$ & +3.30 & $<0.001^{\mathrm{a}^{*}}$ \\
\hline
\end{tabular}

Note. *: $\mathrm{p}<0.001$; a: Mann-Whitney U test; b: Independent samples t-test.

Minimum and maximum hoop D scores were 5.80 and 12.10 respectively in 2018. While the same scores were checked for 2020 it was found that minimum and maximum values were increased to 8.60 and 17.20 points respectively. These increases were similar for the ball (minimum 8.00, maximum 11.40 points in 2018; minimum 8.30, maximum 16.90 in 2020) and clubs D scores (minimum 6.40, maximum 11.30 in 2018; minimum 7.70, maximum 17.40 in 2020). Only ribbon minimum D scores were lower in 2020 than in 2018 (6.90 and 5.80 respectively). Even though minimum D scores seemed to be lower in 2018 maximum D scores were higher than all other D scores (10.20 and 14.40 respectively). Correspondingly, all maximum total scores were higher in 2020 than in 2018.

According to the comparison of scores by year and apparatus, D scores and total scores of each apparatus showed statistically significant differences between years (Figure 1, 2, 3, 4). D scores of all four apparatus increased from 2018 to $2020 \mathrm{ECh}$. The highest increase was for clubs D ( +4.79 points higher than the $2018 \mathrm{D}$ score). The lowest increase was for ribbon $\mathrm{D}$ score by +3.62 points. In addition to these increases total scores for all four apparatus also showed statistically significant differences and they were all higher in 2020. The highest increase was for clubs total score ( +4.46 points higher than 2018), and the lowest increase was found for ribbon D score by +3.30 points raise. In contrast with all these increases in D and total scores, E scores of all four apparatus showed no statistically significant differences between 2018 and 2020. Even though E scores showed no significant differences it is seen that they decreased between 2018 and 2020 (Table 3). 

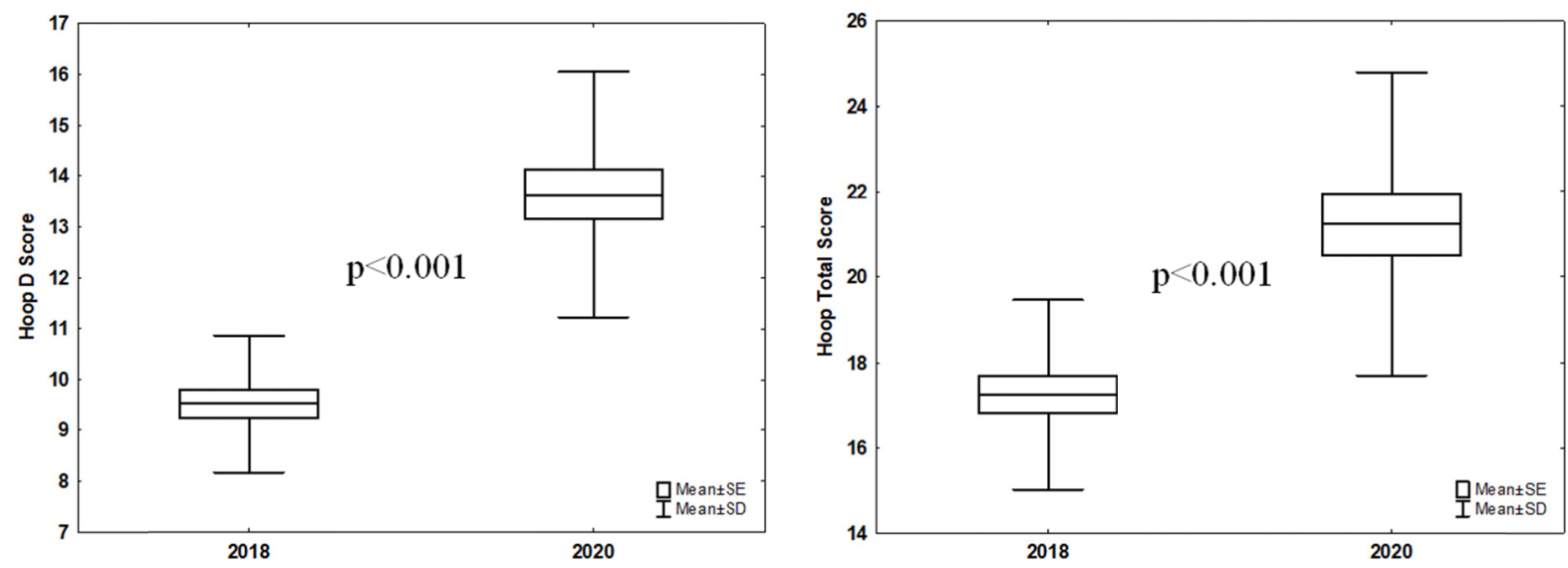

Figure 1. Box plot graphs of hoop D and hoop total scores
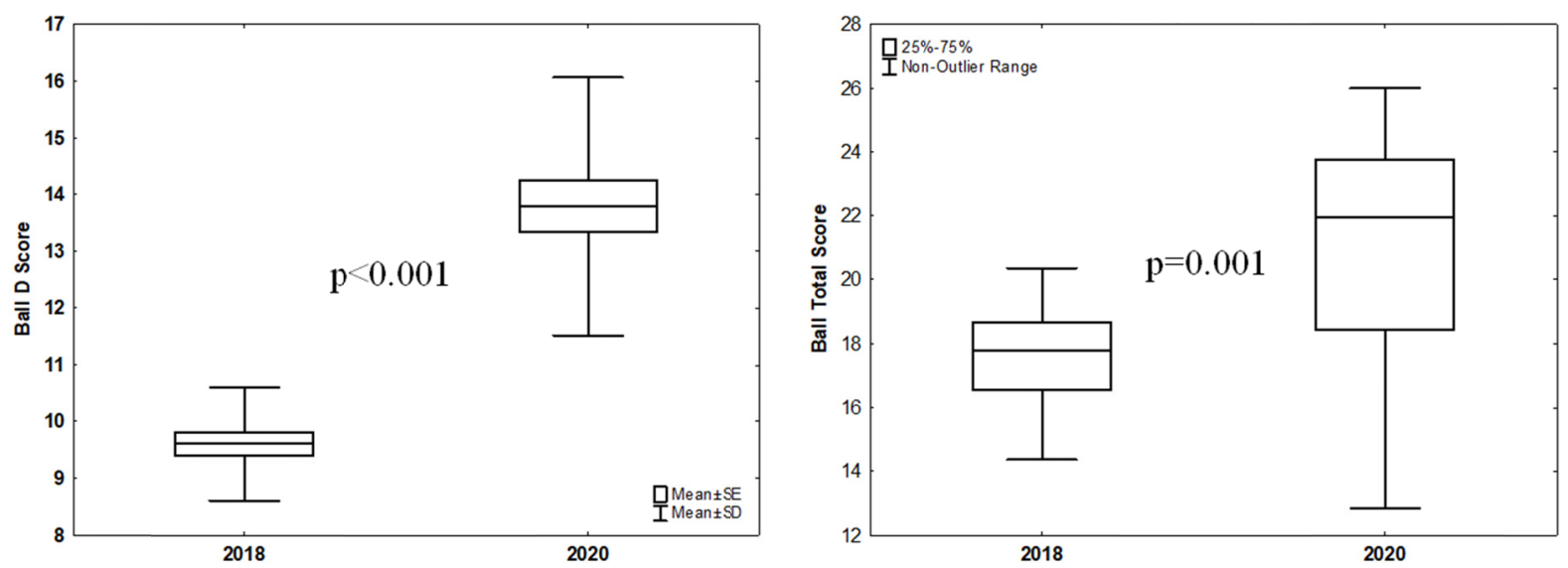

Figure 2. Box plot graphs of ball D and ball total scores
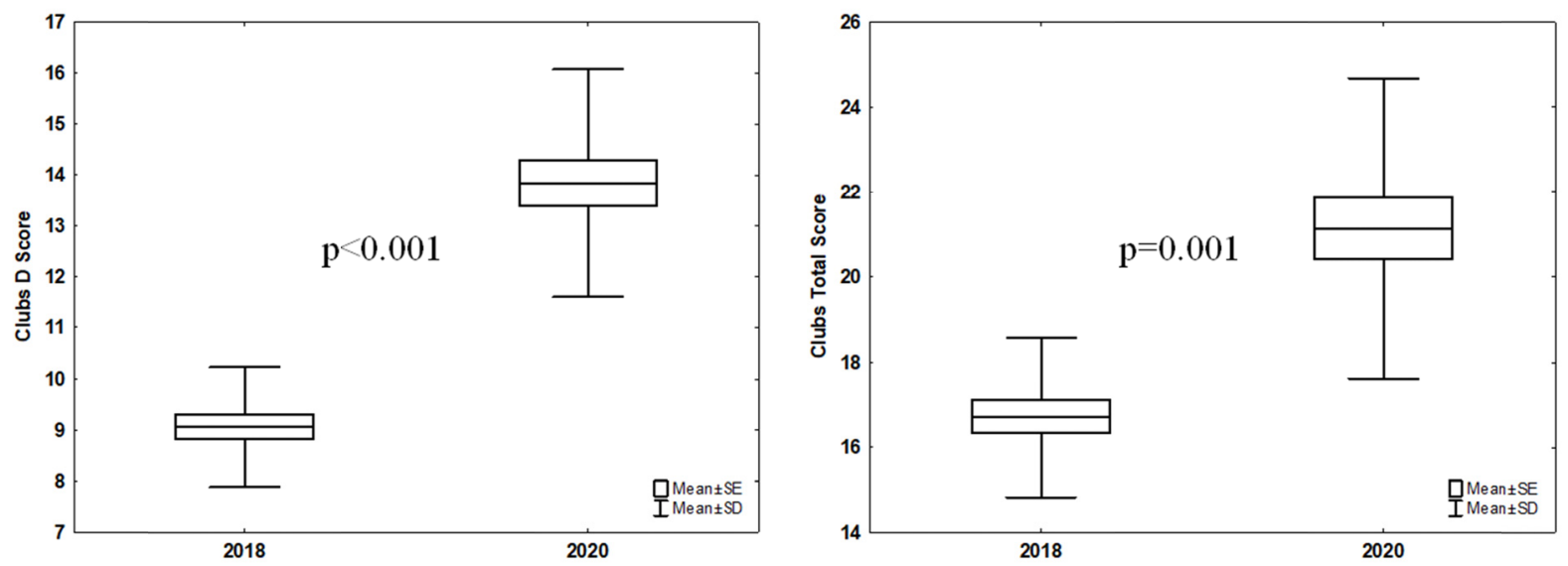

Figure 3. Box plot graphs of clubs D and clubs total scores 

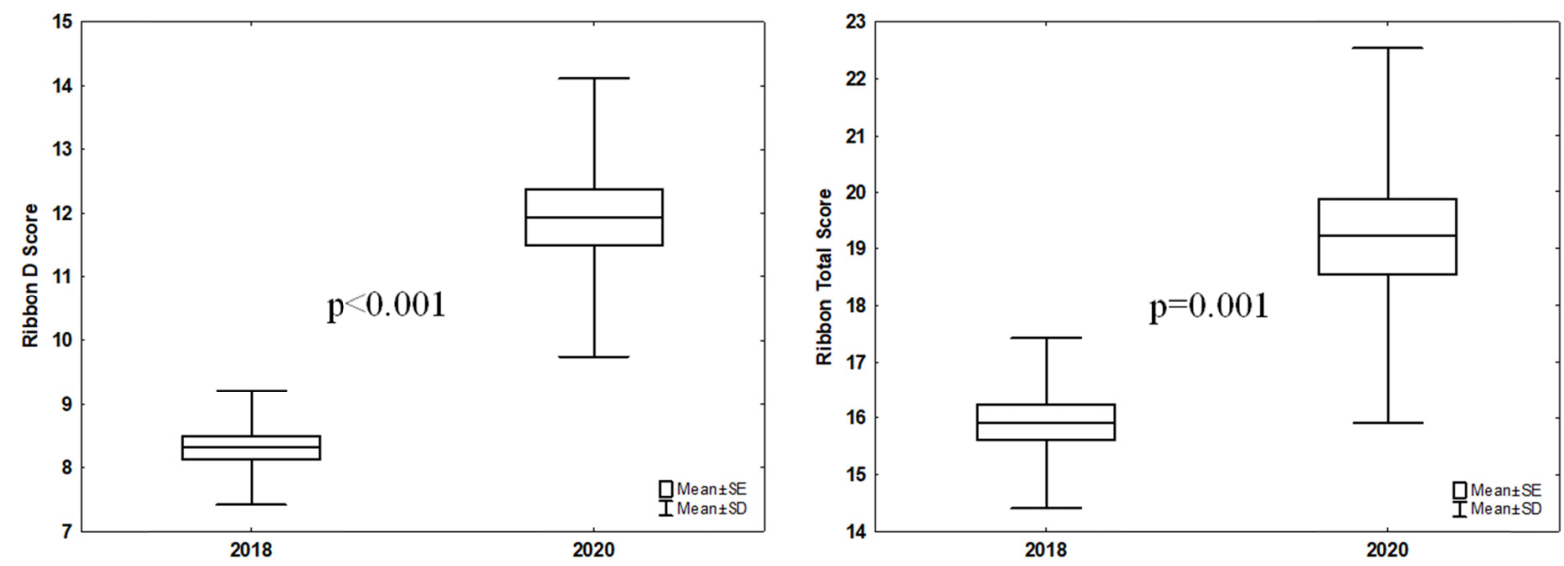

Figure 4. Box plot graphs of ribbon D and ribbon total scores

\section{Discussion}

This study aimed to compare the scores of the first 24 gymnasts who competed in the $34^{\text {th }}$ Rhythmic Gymnastics European Championships-2018 (Guadalajara) and the $36^{\text {th }}$ Rhythmic Gymnastics European Championship-2020 (Kyiv), which was considered as senior individual all-around finals. To our knowledge, this study has been the first to analyze the changes in the D, E, and as well as total scores in two different European Championships in one Olympic cycle with the same rules.

The main finding of the current study was that D scores between 2018 and 2020 increased approximately 4.18 points while $\mathrm{E}$ scores decreased 0.31 points. When only total scores were taken into consideration, it had been determined that in all apparatus the total scores increased (a minimum of +3.30 for ribbon and a maximum of +4.46 for clubs). Furthermore, total ribbon D scores (sum of 2018 and 2020 ribbon D scores) were found to be significantly different and lower than hoop and ball D scores. Finally, the ball total score (sum of 2018 and 2020 total ball scores) was significantly different and higher than the ribbon. According to the results of the current study, it is obvious that gymnasts started to perform a higher number of elements to get higher D and correspondingly higher total scores.

Rhythmic gymnastics is an Olympic sport event and, as in all sports, the technical content of rhythmic gymnastics is changing and increasing rapidly (Agopyan, 2020). Therefore, FIG updates CoP regularly (every four years) to create clarified judging criteria, enhance objectivity, diminish injury risks and improve the quality (Chiriac, Teodorescu \& Bota, 2019). At the end of 2017, the maximum limit for D score was removed by the FIG rhythmic gymnastics technical committee. This change led to substantial modifications in the related scores and therefore in the final scores (Chiriac et al., 2020). Chiriac et al. (2020) reported the all-around final scores of the senior individual world champion, from 2017 to 2019. According to this report, the champion's score increased from 74.70 to 91.40 in two years. In the present study, The European champion's total scores for 2018 and $2020 \mathrm{ECh}$ raised from 79.25 to 100.90 points. These results seem to support the previous research (Chiriac et al., 2020).

Rhythmic gymnastics is going through a difficult transition period, facing major changes over the last decade, with every change and each new edition of the FIG Code of Points (Chiriac et al., 2020). In the literature, it is reported that the previous evaluation system (2009-2012 FIG Code of Points) had a negative impact on coaches because they prepared routines by emphasizing technique and execution quality. As a result, some of the artistic requirements were taken less into consideration and were usually inappropriately evaluated (Manos \& Popescu, 2014). According to the results of the current study, while an increase of $D(+4.12$ for hoop, +4.19 for ball, +4.79 for the clubs, +3.62 for the ribbon) and total scores $(+4.01$ for the hoop, +3.60 for the ball, +4.46 for the clubs, +3.30 for the ribbon) were obtained, in contrast, there were no significant changes for E scores which also contain artistic components. As European Gymnastics does not publish results in subgroups, in the present study the analysis was conducted only by total $\mathrm{D}$ and $\mathrm{E}$ scores. Therefore, it was not possible to analyze $\mathrm{D}\left(\mathrm{D}_{1-2}, \mathrm{D} 3_{-4}\right)$ and $\mathrm{E}$ scores $\left(\mathrm{E}_{1-2}\right.$ and $\left.\mathrm{E}_{3-4-5-6}\right)$ in subgroups. But, considering the changes in these two scores it is thought that even though FIG changed the rules after the 2016-Rio Olympic Games, a similar approach from the previous cycle remains for coaches. The D score increases can be explained in three ways: Firstly, according to rules, there is no upper limit for the number of BDs performed but the correctly performed highest nine are evaluated (FIG, 2017). Therefore, to get higher D scores, gymnasts may prefer to perform BDs with higher values. To get higher values of 
BDs a gymnast may add some additional criteria to jumps such as ring position and backbend of the trunk. But, considering that there is no upper limit for use of ADs (FIG, 2017) it is more realistic that gymnasts preferred to have more ADs. Secondly, gymnasts may get 0.30 for one dance steps combination (minimum eight seconds), and instead of spending eight seconds to get only 0.30; probably they preferred to have two or three ADs (considering the minimum value for $\mathrm{AD}$ is 0.20 and the maximum value is 0.40 , gymnasts may get approximately 0.60 in the same time interval as dance steps). Lastly, according to rules, gymnasts may perform a maximum of five dynamic elements with rotation. But, they can get higher scores for DER by adding criteria such as catch without the help of the hands, throw out of visual control, etc. (FIG, 2017). For this reason, to get higher D scores in $2020 \mathrm{ECh}$; gymnasts probably perform a similar number of DER but with higher values than $2018 \mathrm{ECh}$. In all ways, it is obvious that rules and coaches force gymnasts to have more elements in a routine while the required time for an individual routine remains the same in each rule change (1'15" - 1'30") (FIG, 2017).

Chiriac et al. (2019) analyzed body difficulties in junior rhythmic gymnasts according to CoP and they reported the highest number of difficulty elements in a routine was 23 with a total of $9.80 \mathrm{D}$ score spending time $(1: 21: 37$ $\mathrm{m} / \mathrm{sec} / \mathrm{ms}$ ) to perform all D elements (BD, AD, dance steps, DER). Furthermore, the winner of the competition spent less time $(1: 16: 05 \mathrm{~m} / \mathrm{sec} / \mathrm{ms})$ performing 22 elements and achieved the same $\mathrm{D}$ score. The authors stated that the time difference between these gymnasts $(0: 05: 32 \mathrm{~m} / \mathrm{sec} / \mathrm{ms})$ allowed the winner to fulfill the artistic criteria such as; arm movements, stylized connection steps, connections between elements, and body waves (Chiriac et al., 2019). Considering preparation facilities among the whole rhythmic gymnastics' world and the gymnasts' characteristics, it is obvious that every country or gymnast cannot have these high D scores. Each gymnast cannot have higher technical capacities but gymnasts with less technical abilities may perform effective artistic components to create dance, art, and sport in one routine. Unfortunately, current rules do not allow gymnasts to show their artistic abilities but only force gymnasts to perform elements with higher numbers and values. This pressure is maybe not only physical but also mental and psychological. Unfortunately, these topics were not analyzed in this study. Analyzing the physical, mental and psychological situation of gymnasts may provide useful information to the literature.

In conclusion, gymnasts are trying to perform a high number of elements to get higher scores. With these results, it can be hypothesized that rhythmic gymnasts with increasing D scores over two years might have an increased risk of injuries, physical and psychological pressure for gymnasts. To perform such tense routines with so many difficulties and elements, gymnasts have to train for hours and the training process in RG has high demands in terms of both volume and intensity (Bobo-Arce \& Méndez-Rial, 2013). To attain perfection and reproducibility of routines, gymnasts need to practice and repeat elements many times. These huge number of repetitions is reported to put a risk on gymnasts' health (such as overuse injuries, low back pain, etc.) (Hutchinson, 1999). This kind of extensive training amounts and the integration of more technically challenging routines of gymnasts increase their risk of injury (Law, Côté \& Ericsson, 2007). In addition to physical abilities and components, psychological characteristics are another important determinant of performance (Zisi, Giannitsopoulou, Vassiliadou, Pollatou \& Kioumourtzoglou 2009). By rapid increases in sports performance, coaches and all other people involved in the training and competitive performance should influence the athlete's personality structure (Manos \& Popescu, 2019). Considering that gymnastics is an early-specialization sport and gymnasts start training at the age of 5-7 they start to specialize in gymnastics by the age of 9-11 (girls). When gymnasts are 10-13+ years old (12-15+ years for boys) they start to be a consistent competitor (Temürçi, Bayraktar, \& Nalbant, 2020) and try to set a standard for being professional. On the other hand, it is accepted that this is the stage of puberty and more emphasis should be placed on emotional and social issues (Balyi et al., 2013). As a result of D score increases (a minimum of +3.12 increase for ribbon and a maximum of +4.79 points for clubs) over two years, it can be hypothesized that with such high demands of the training process and high score expectations gymnasts are facing both physically and mentally hard times.

According to Zetaruk et al. (2006) while limiting training hours to a maximum of 30 hours per week may reduce fractures and limiting training hours to a minimum of 20 hours per week may reduce muscle-tendon unit injuries. Unfortunately, in contrast with these suggestions, gymnasts all over the World have to train for longer hours. For example, Debien et al. (2019) analyzed the weekly profile of training load in elite rhythmic gymnasts and reported that in a preparatory period gymnasts train 36 hours and 40 minutes. Furthermore, during the competitive period gymnasts train for 32 hours and 20 minutes. In both situations, gymnasts train more than the recommended durations. Considering the results of the current study and score increases (approximately +4.00 points for D and correspondingly for total scores) there is a chance that gymnasts had to train even more hours and as a result, they are probably at risk of injuries. 


\section{Conclusion}

According to the results of the current study, it is obvious that $\mathrm{D}$ and total scores increased during two years. And the highest increase was found in clubs' $\mathrm{D}$ score with +4.79 points and correspondingly +4.46 points for total clubs score. The lowest increases were found for ribbon D and total scores; +3.62 and +3.30 points respectively. In contrast with these significant differences and increases, none of the E scores showed significant differences between years. But, even though, E scores were not significantly different, it was seen that they were lower in 2020 than in 2018. In all cases, it is obvious that gymnasts were forced to perform much more elements (such as BDs and ADs) to increase their D scores in two years. Interestingly, the required duration of a routine did not change and gymnasts had to perform these higher number of elements in the same time duration (minimum 1'15 and maximum 1'30"). Therefore, probably they were supposed to be faster to perform all elements. To become faster and better at their elements they may have trained for hours and hours which can cause physical, mental, and psychological effects on gymnasts' health. On the other hand, even though the difficulty level of routines increased coaches may have had no notice on the artistic part of the routines to get higher D scores. This may cause routines to become more complicated for both judges and audiences. With this view, rhythmic gymnastics is losing its beauty and artistic part which consists of art, dance, music, and sport. Because rhythmic gymnastics is not only an Olympic competitive sport but also a combination of art, dance, and aesthetics. Unfortunately, with recent changes in the rules and all these increases in D scores and correspondingly total scores both the gymnasts' health and the beauty of the sport may be at risk. To allow gymnasts to show their skills (such as artistry) some changes should take place in the rules. For example, the duration and value for a dance steps combination can be changed. By increasing the values and shortening the duration coaches will have a chance to choose dance steps over ADs. Dance steps are usually easier to perform and without any doubt, they change the structure of the routines in a good way. According to the current rules, gymnasts are allowed to perform one $\mathrm{AD}$ (without any pre-acrobatic elements such as rolls, walkovers, etc.) during a dance steps combination. This rule may also change. If gymnasts are not allowed to perform any AD during dance steps combination then they may have a chance to show their artistic abilities without concerning about any technical elements. Besides, some changes in E scores may also take place.

The results of the current study indicate that $\mathrm{D}$ scores of all four apparatuses (hoop, ball, clubs, and ribbon) increased during two years period. As these increases seem to be in the faith of gymnasts to have higher results, it is obvious that people (coaches, judges, etc.) who are involved in gymnasts' training and competition process should also consider the gymnasts' health by all odds. For this reason, FIG should update the rules considering the health of the gymnasts (physically, psychologically and mentally).

In conclusion, some coaching and training educations may take place to change the traditional way of training in rhythmic gymnastics. Because as gymnasts are starting training at a very young age this intensive training are becoming a part of their life and when they stop their career and become coaches, they perform similar training methods on the upcoming generations. To change this traditional system, some coaching educations, new training models should be presented to the rhythmic gymnastics world. With the recent changes and updates in the whole sports sciences, coaches should be informed about new training models and coaching education systems. In this way, coaches will be able to support their gymnasts in all ways (not only with performance development but also with recent updates on training educations).

A limitation of this study is only two European Championships were considered in this study. In future studies, all of the European Championships in an Olympic cycle can be examined. Besides, by the rapid technical development in this sport, it should be investigated how the trainers changed their training and what different methods they use to protect the health of the athletes should be investigated. Another limitation is, this study only covers senior individual rhythmic gymnasts. Similar studies can be done with the junior and/or groups by analyzing subgroup scores. This will provide useful information to analyze the routines during European Championships to determine the increases in D scores specifically.

\section{References}

Agopyan, A. (2014). Analysis of body movement difficulties of individual elite rhythmic gymnasts at London 2012 Olympic games finals. Middle - East Journal of Scientific Research, 19(12), 1554-1565.

Agopyan, A. (2020). An analysis of movements with or without back bend of the trunk or large hip extension in 1st Juniors' Rhythmic Gymnastics World Championship-2019. Is there injury risk for gymnasts? International Journal of Performance Analysis in Sport, 2021, 21(1), 108-125. https://doi.org/10.1080/24748668.2020.1850038

Agopyan, A., \& Örs, B. S. (2019). An analysis of variations in body movement difficulty of 2016 Olympic Games rhythmic gymnast candidates. International Journal of Performance Analysis in Sport, 19(3), 
417-434. https://doi.org/10.1080/24748668.2019.1617017

Ávila-Carvalho, L., Klentrou, P., \& Lebre, E. (2012). Handling, throws, catches and collaborations in elite group rhythmic gymnastics. Science of Gymnastics Journal, 4(3), 37-48.

Balyi, I., Way, R., \& Higgs, C. (2013). Long-Term Athlete Development. In Current Sports Medicine Reports (Vol. 9, Issue 6). Human Kinetics. https://doi.org/10.5040/9781492596318

Batista, A., Gomes, T. N., Garganta, R., \& Ávila-Carvalho, L. (2018). Training intensity of group in rhythmic gymnastics. Ovidius University Annals, Series Physical Education \& Sport/Science, Movement \& Health, 18(1), 17-24.

Bobo-Arce, M., \& Méndez-Rial, B. (2013). Determinants of competitive performance in rhythmic gymnastics. a review. Journal of Human Sport and Exercise, $8(3$ PROC), 711-727. https://doi.org/10.4100/jhse.2013.8.Proc3.18

Bulca, Y., \& Ersöz, G. (2004). The effects of exercise and nutrition on growth in rhytmic gymnasts. Gazi Journal of Physical Education and Sport Sciences, IX(2), 11-20.

Chiriac, S., Teodorescu, S., \& Bota, A. (2020). Preliminary study on psychomotor abilities decisive for technical routines in rhythmic gymnastics. BRAIN. Broad Research in Artificial Intelligence and Neuroscience, 11(4), 62-80. https://doi.org/10.18662/brain/11.4Sup1/156

Chiriac, Ștefania, Teodorescu, S., \& Bota, A. (2019). Body difficulties in junior rhythmic gymnastics according to the fig code of points. Discobolul - Physical Education, Sport and Kinetotherapy Journal, 48-55.

Debien, P., Miloski, B., Timoteo, T., Ferezin, C., \& Filho, M. B. (2019). Weekly profile of training load and recovery in elite rhythmic gymnasts. Science of Gymnastics Journal, 11(1), 23-36.

Di Cagno, A., Fiorilli, G., Iuliano, E., Tsopani, D., Buonsenso, A., Piazza, M., \& Calcagno, G. (2018). Disordered eating behaviors in rhythmic gymnasts: A survey to investigate the coaches' point of view on the management. Journal of Physical Education and Sport, 18(3), 1748-1755.

Díaz-Pereira, M. P., Gómez-Conde, I., Escalona, M., \& Olivieri, D. N. (2014). Automatic recognition and scoring of olympic rhythmic gymnastic movements. Human Movement Science, 34(1), 63-80. https://doi.org/10.1016/j.humov.2014.01.001

FIG. (2017). Code de Pointage Gymnastique Rythmique: 2017-2020 (F. I. De Gymnastique-FIG (ed.); FIG, comit).

Hutchinson, M. R. (1999). Low back pain in elite rhythmic gymnasts. Medicine and Science in Sports and Exercise, 31(11), 1686-1688. https://doi.org/10.1097/00005768-199911000-00027

Law, M. P., Côté, J., \& Ericsson, K. A. (2007). Characteristics of expert development in rhythmic gymnastics: A retrospective study. International Journal of Sport and Exercise Psychology, 5(1), 82-103. https://doi.org/10.1080/1612197X.2008.9671814

Manos, M., \& Popescu, L. (2014). The Impact Induced by the 2009-2012 FIG Code of Points on Artistic Compositions in Rhythmic Gymnastics Group Events. Procedia - Social and Behavioral Sciences, 117, 300-306. https://doi.org/10.1016/j.sbspro.2014.02.217

Manos, M., \& Popescu, L. (2019). The psychological profile of group rhythmic gymnasts. Discobolul - Physical Education, Sport and Kinetotherapy Journal.

Morley, B., \& Thomas, D. (2005). An investigation of home advantage and other factors affecting outcomes in English one-day cricket matches. Journal of Sports Sciences, 23(3), 261-268. https://doi.org/10.1080/02640410410001730133

Örs, B. S. (2020). The effect of difficulty and execution scores on total ranking during 2019 Rhythmic Gymnastics World. African Educational Research Journal, 8(1-Sp), 37-42. https://doi.org/10.30918/AERJ.8S1.20.005

Sierra-Palmeiro, E., Bobo-Arce, M., Pérez-Ferreirós, A., \& Fernández-Villarino, M. A. (2019). Longitudinal study of individual exercises in elite rhythmic gymnastics. Frontiers in Psychology, 10(1496), 1-7. https://doi.org/10.3389/fpsyg.2019.01496

Temürçi, İ., Bayraktar, I., \& Nalbant, Öz. (2020). The early specialization requiring sport of gymnastics and long-term athlete development programs. The Online Journal of Recreation and Sport, 9(4), 19-28. https://doi.org/10.22282/ojrs.2020.74 
Trifunov, T., \& Dobrijević, S. (2013). The structure of difficulties in the routines of the best world and serbian rhythmic gymnasts. Fizička Kultura, 67(2), 120-129. https://doi.org/10.5937/fizkul1302120T

Zetaruk, M., Violán Fors, M., Zurakowski, D., Mitchell Jr., W., \& Micheli, L. (2006). Injuries and training recommendations in elite rhythmic gymnastics. Apunts: Medicina de l'esport, 41(51), 100-106. https://doi.org/10.1016/S1886-6581(06)70018-4

Zisi, V., Giannitsopoulou, E., Vassiliadou, O., Pollatou, E., \& Kioumourtzoglou, E. (2009). Performance level, abilities and psychological characteristics in young junior rhythmic gymnasts: The role of sport experience. International Quarterly of Sport Science, 4, 1-13.

\section{Copyrights}

Copyright for this article is retained by the author(s), with first publication rights granted to the journal.

This is an open-access article distributed under the terms and conditions of the Creative Commons Attribution license (http://creativecommons.org/licenses/by/4.0/). 